\title{
Announcement: Galileo Galilei Award
}

The Galileo Galilei Award in Medical Physics is given every second year to the best paper published in this journal in the previous two years. Starting from 2014, the Award will be assigned each year to the best paper published in this journal in the previous year.

The prize has been previously awarded to:

- For the years 1999-2000: L.Bogner, J.Scherer, M.Herbst "An inverse Monte Carlo optimization algorithm for conformal therapy", Phys Med 1999; XV(3):111-119.

- For the years 2001-2002: B.Schmidt and W.Kalender "A first voxel-based Monte Carlo method for scanner- and patient-specific dose calculations in Computed Tomography”, Phys Med 2002; XVIII(2):43-53.

- For the years 2003-2004: M.Durante "Potential applications of biomarkers of radiation exposure in nuclear terrorism events", Phys Med 2003; XIX(1):191-212.

- For the years 2005-2006: B.C.Ferreira "Effective beam directions for biologically optimized IMRT of node positive breast cancer", Phys Med 2006; 22(1):3-15.

- For the years 2007-2008: H.Gay and A.Niemierko "A free program for calculating EUD-based NTCP and TCP in external beam radiotherapy", Phys Med; 23(3):115-125.

- For the years 2009-2010: M.Conti "State of the art and challenges of Time-Of-Flight PET", Phys Med March 2009; 25(1):1-11.

- For the years 2011-2012: "CT iterative reconstruction in image space: A phantom study", Phys Med April 2012; 28(Issue 2):161-165.

Physica Medica - the European Journal of Medical Physics is happy to announce that the paper "Iterative reconstruction methods in two different MDCT scanners: Physical metrics and 4alternative forced-choice detectability experiments - A phantom approach" by Frédéric A. Miéville, François Gudinchet, Francis Brunelle, François O. Bochud, Francis R. Verdun, published in Physica Medica, Volume 29, Issue 1, January 2013, Pages 99-110, has been elected the best paper published in the journal in the year 2013.

In that paper the authors present an investigation on radiation dose reduction and improved image quality in X-ray Computed Tomography imaging, carried out by evaluating three different commercial CT iterative reconstruction methods. This clear and effective scientific report showed the potential of such methods in improving the quality and reducing the patient dose in CT imaging, of particular interest for pediatric patients, highlighting the role of medical physicists in the assessment of diagnostic imaging procedures.

The selection of the best paper has been performed on the basis of citations and downloads together with the assessment by the Editors, Associate Editors and members of the Editorial Board.

We congratulate the authors, Dr. F. A. Miéville, Dr. F. Gudinchet, Dr. F. Brunelle, Dr. F. O. Bochud, Dr. F. R. Verdun, from the Institute of Radiation Physics and the Department of Radiology, University Hospital Center and University of Lausanne, Lausanne, Switzerland, and from the Department of Radiology, Necker Children's Hospital and University Paris Descartes, Paris, France, as the winners of the Galileo Galilei Award 2013.

Galileo Galilei's book Dialogo sopra $i$ due massimi sistemi del mondo (Dialogue concerning the two chief world systems) was published by Giovan Batista Landini in Florence in 1632 in Italian; in 1635, Elsevier in Leiden published the first Latin edition, printed in Strasbourg: the engraved title page of this book is reproduced aside.

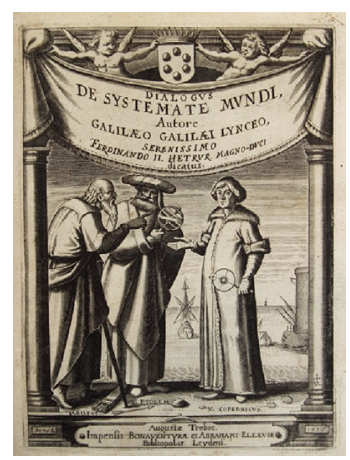

Physica Medica: European Journal of Medical Physics is published by Elsevier B.V. for the European Federation of Organisations for Medical Physics (EFOMP) and Associazione Italiana di Fisica Medica (AIFM). EJMP is the official journal of the Irish Association of Physicists in Medicine and Société Française de Physique Médicale. 